\title{
SISTEM PENILAIAN KARYA SENI RUPA DAN KERAJINAN
}

\section{Suharto}

\section{Fakultas Bahasa dan Seni Universitas Negeri Yogyakarta}

\section{Abstract}

This writing is aimed to give wider concept to society or readers especially for candidates of fine art teacher to make assessment for fine art works. It is indeed such a standard, but a candidate of assessor must be able to make and have an objective assessment. The results show that assessing fine arts both pure fine art and applied ones can be viewed from some point other than fine art structure viewing only idea in the form of message, imagination, illusion, desire, and fantasy of the artist other than considering work physical form element, principle, media and effective technique. There are some ways to assess a work from aesthetical side resulted in the writing. Firstly, the presence of initial reaction (clarifying initial identification) of an art work. Secondly, intal the at elents inct the art elenents inclung: line, plane, color, value, format, texture, and space. Another, there are design principles consisting of balance, harmony, central, interest, movement, proportion, restriction, model pattern, rhythm, unity, and variety. Beside considering fine art elements, it also requires to consider design elements including : balance, emphasis, euryhmy, harmony, horror vacui, limitation, movement, pattern proportion, rhythm, unity, and variety. Elements and principles are much higher to consider the design and closer with its pure art consideration of using fine art component consisting of theme or subject matter, form, and meaning or content. Thirdly, analyzing by further identification on order of organization in an art work as art principles used to arrange art elements in an art work. Fourthly, interpretation of meaning as a communication form the artist to feel the atmosphere and idea in the art work by considering the history, creative process, envirent, and economy. Fifthly, evition, and econ both on meaning and artistic serice in the ant wok. The benefit expected from the research is giving the public wider insight to know more on the assessment of fine art works that the common society and academician know qualified art work objectively and subjectively.

Kata kunci: penilaian, karya seni, dan proses evaluasi

\section{PENDAHULUAN}

Menilai hasil karya seni rupa baik itu lukisan, patung, dan grafis tidaklah mudah untuk dipahami oleh masyarakat akademis maupun masyarakat yang buta akan seni. Barang kali kita dapat melihat karya seorang pelukis Joko Pekik yang harganya mencapai puluhan juta, demikian dengan Amri Yahya, Affandi, Joko Maruto, dan sebagainya, yang mana penilaian lukisan ini sangat bersifat subjektif dalam penilaiannya, bai secara estetis maupun dari segi ekonomis. 
Sistem penilaian terhadap karya seni rupa di Sekolah Dasar, SMP, SMU dan perguruan tinggi masih mengalami kerancuan atau masih dinilai secara subjektif oleh para pengajarnya. Dalam menilai suatu karya lukisan kita dapat berpedoman pada sembilan hal berikut: tema, dasar pemikiran, estetis, historis, proses kreatif, lingkungan, sosial, politis, proses kreatif, dan ekonomis. Namun bukan berarti dalam penilaian sebuah lukisan harus memenuhi semua faktor tersebut, melainkan kita dapat melihat dari sudut mana sebuah kesepakatan penilaian itu diberikan (subjektif).

Dari latar belakang di atas dapat ditarik beberapa permasalahan antara lain, dapatkah masyarakat umum menilai karya seni rupa dan dapatkah kalangan akademis di lingkungan UNY menilai karya seni rupa baik dari seg kemampuan, unsur seni rupa, prinsip desain dan menginterpretasikan karya tersebut dalam inovasi, proses kratif lingkungan, syarat, sosial politik, budaya, filsafat, dan ekonomi.

Untuk menilai sebuah karya dari segi estetis ada beberapa langkah Langkah-langkah dan mekanisme penilaian sebagaimana tampak pada bagan 1 .

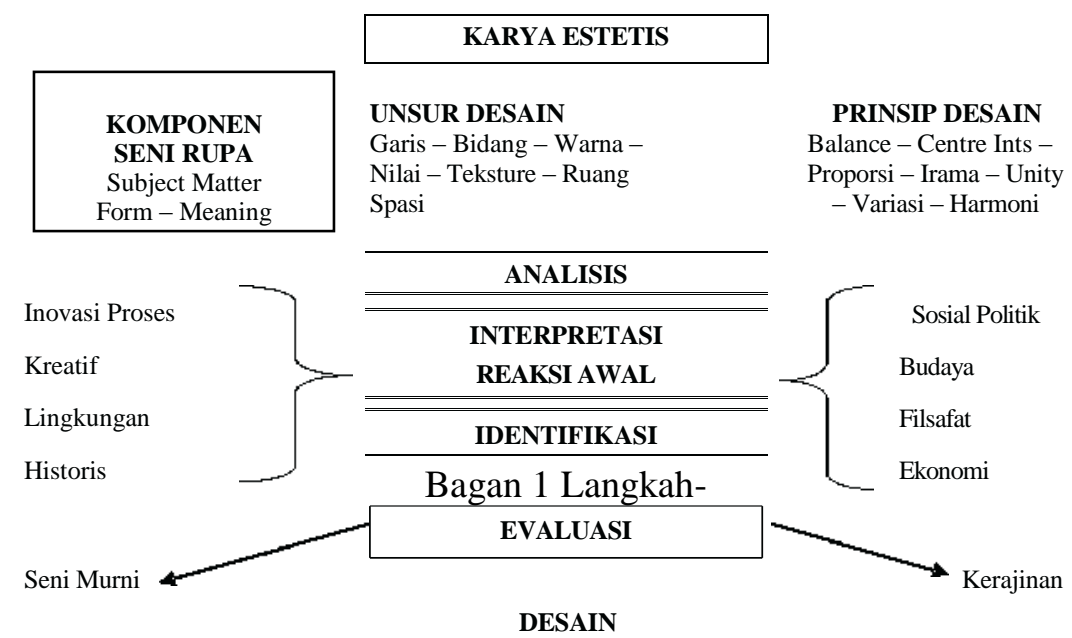

langkah dan mekanisme penilaian

\section{ASPEK DAN MEKANISME PENILIAN KARYA SENI}

\section{Komponen Seni Rupa}

Pembahasan tentang komponen seni rupa meliputi tiga hal, yakni (1) tema (subject matter), (2) bentuk (form), dan (3) isi (meaning). Dalam teori organis yang dikemukakan oleh Weitz, disebutkan bahwa tema merupakan sesuatu yang diacu dalam karya seni (yang dijadikan sebagai pokok permasalahan) yang disebut objek atau sasaran dari karya yang bersangkutan. Berkaitan dengan tema, subject matter adalah subyek yang merupakan pokok permasalahan atau isi. Dalam hal ini bisa berupa orang, benda, pemandangan, atau peristiwa yang berada di luar karya seni tersebut.

The Liang Gie (dalam Sahman, 1994) mengatakan bahwa pokok isi atau subject matter adalah apa yang hendak diketengahkan karya seni yang mencakup benda atau peristiwa yang telah kita kenali lewat pengalaman kita. Jadi, Subject Matter adalah sesuatu yang sangat substansial yang menunjuk pada isi pokok karya seni.

Dari pendapat di atas dapat diketahui bahwa Subject Matter bermula dari apa yang dianggap hakiki dari yang diamati seniman. Hal tersebut telah melewati pengalaman estetik dan pengolahan batiniah seniman yang kemudian diwujudkan dalam karya seni. Dalam batiniah seniman berhubungan erat dengan visi yang sifatnya individualistis, amak akan terjadi Subject Matter yang berbeda walaupun menghadapi objek yang sama.

Form yang dimaksud di sini adalah bentuk dalam pengertian paling luas, total struktur, sintesa dari semua aspek yang terlihat menyangkut struktur cara yang disatukan untuk menciptakan karakter khusus. Format suatu pekerjaan adalah sesuatu yang memungkinkan kita untuk menangkap atau mengerti. Form juga mengacu pada unsur seni tiga dimensi (tinggi, lebar, dan kedalaman) dan termasuk volume.

Misalnya suatu segitiga, ketika berbentuk dua dimensi maka merupakan suatu bentuk, tetapi ketika berbentuk tiga dimensi (piramida) maka ia adalah suatu format. Kubus, belah ketupat, piramida, kerucut, dan silinder adalah contoh berbagai format, juga semua unsur suatu seni karya yang tidak terikat pada makna atau arti. Unsur-unsur formal merupakan corak utama yang bukan sesuatu yang bersifat semantik - mencakup warna, dimensi, garis, massa, media, skala, bentuk (ruang), tekstur, nilai, dan prinsip-prinsip desain di bawahnya - yang meliputi mencakup keseimbangan, kontras, kekuasaan, keselarasan, pergerakan, proporsi, kedekatan, irama, persamaan, dan variasi.

Aspek nilai (meaning) bukanlah suatu objek, karenanya ia tak memiliki sifat yang objektif. Nilai merupakan suatu konsep, yakni pembentukan mental yang dirumuskan dari tingkah laku manusia sehingga menjadi sekumpulan anggapan yang hakiki, baik dan perlu dihargai sebagaimana mestinya. Lebih lanjut, nilai menyediakan prinsip umum dan menjadi acuan serta tolak ukur standar dalam membuat keputusan, pilihan tindakan dan tujuan tertentu bagi para anggota masyarakat (Yudistira, 1996)

\section{Unsur-Unsur Desain}

Unsur Garis

Garis adalah suatu goresan, batas limit suatu benda, massa, ruang, warna 
dan sebagainya (Sidik, 1979). Menurut Dana Marjono dan Suyatno (1990) Garis adalah kesatuan dari beratus-ratus titik bahkan tak terhitung banyaknya. Kalau letaknya itu searah dan seletak dalam satu kesatuan disebut garis lurus. Kehadiran unsur garis sangatlah penting dalam proses menggambar ilustrasi karena garis dapat menjadi alat bagi seniman atau ilustrator untuk mengekspresikan perasaan dan bentuk-bentuk yang diinginkan.

Dalam karya patung, garis dapat berupa tepi suatu bidang atau ruang dari suatu bentuk (form), atau sebagai kontur (garis luar) suatu benda. Garis dapat menggambarkan massa, ruang, tekstur, cahaya, dan bayangan. Garis juga dapat menonjolkan bentuk, dan menciptakan suasana perasaan ( $\mathrm{mood})$.

Garis adalah suatu tanda dengan panjang dan arah (direction). Suatu unsur seni yang mengacu pada garis menyambung yang terbentuk oleh beberapa titik. Jenis garis meliputi: vertikal, horizontal, diagonal, dikuasai, dibengkokkan, disela, atau lebar/luas, lurus/langsung (yang diberi titik, dihancurkan, patah/dirusakkan, dan lain-lain), tidak jelas, dikendalikan atau blurred, buatan tangan, pararel, mengarsir, kelok-kelok, dan berpilin. Garis dapat menggambarkan suatu ruang, spasi, dan dapat menciptakan suatu garis besar atau sekeliling, menggambarkan suatu bayangan hitam, menciptakan pola acuan, atau pergerakan, dan ilusi massa atau volume.

\section{Unsur Bidang Datar}

Contoh karya di mana bidang merupakan elemen penting: Pablo Picasso, Bottle of Vieux Marc, Glass, Guitar, dan Newspaper, 1913. Susunan pena dan d atas kertas biru, $46.762 .5 \mathrm{~cm}$, Tate Gallery, London. Pablo Picasso, salah satu pelukis ulung terbesar, hidup lama dan menghasilkan yang digunakan untuk mengerjakan berbagai gaya. Akan tetapi, periode tersebut dikenal sebagai kubisme analitis. Dengan palet yang terbatas dan hanya tatanan sederhana objek hidup diam, Picasso secara brillian menginvestigasi bagaimana bentuk ada dalam ruang. Kubisme meminta pengamat untuk membahas masalah elemen tentang apa benda yang kita lihat dan pahami secara fisik perbedaan sudut pandang dijalin melalui serangkaian bidang yang tumpang tindih.

Bidang yang dimaksud adalah bentuk sebagian dari keseluruhan struktur yang ada dalam sebuah karya. Misalnya sebuah lukisan berbentuk keseluruhan berupa lingkaran dan didalamnya terdiri dari berbagai bentuk bidang misalnya ada beberapa susunan segi empat ataupun segi lima.

\section{Unsur Warna}

Warna dihasilkan ketika cahaya mengenai suatu objek dan kemudian dipantulkan kembali kemata. Suatu unsur seni dengan tiga sifat. Pertama, warnawarni nama warna, misal merah, kuning, biru, dan lain-lain. Kedua, intensitas, kemurnian dan kekuatan suatu warna, misal merah pudar atau merah terang. Ketiga, value, kecerahan atau kegelapan suatu warna.

Ketika spektrum disusun sebagai roda warna, maka warna dibagi menjadi kelompok warna primer, sekunder dan antara (tersier) utama, analog dan komplementer, dan juga warna panas dan dingin. Beberapa kata yang diguankan untuk menggambar warna yang lebih bersifat subjektif (sesuai pendapat atau cita rasa personal), seperti menggairahkan, manis, sakarin, barsh, berkilat, buruk, cantik, keren, modern, cantik, dan mulia.

\section{Unsur Nilai (Value)}

Value merupakan suatu unsur seni yang mengacu pada gelap atau terangnya suatu warna. Nilai adalah suatu unsur yang penting di dalam karya seni baik ketika warna tidak ada. Nilai terutama sekali berkaitan dengan bidang pekerjaan menggambar, lukisan dari ukiran kayu, tulisan pada batu, dan memotret. Juga pada pahatan dan arsitektur. Perubahan nilai, baik mendadak atau bertahap, bisa memberikan dampak visual yang sangat besar pada bentuk seni. Perubahan nilai juga bisa digunakan untuk membantu seniman mengekspresikan ide.

\section{Unsur Format}

Suatu elemen seni yang mengacu pada kualitas permukaan atau "feel of an object", kehalusan, kekasaran, kelembutan, dan sebagainya. Tekstur bisa bersifat aktual atau simulasi. Tekstur aktual bisa dirasakan dengan jari, sedangkan tekstur simulasi diajukan oleh seorang artis dalam lukisan wilayah lain suatu gambar - sering kali dalam gorden, logam, batu, rambut, dan sebagainya. Kata-kata yang menggambarkan tekstur diantaranya : datar, lembut, berkilau, mengkilat, gemerlap, berbulu, lembut, basah, liat, berbulu lembut, dan sebagainya. Pertahanan demostratif - keengganan yang kuat pada tekstur, material, atau bahkan sentuhan manusia. Dalam seni, keengganan umum meliputi tanah liat dan pasta.

\section{Unsur Ruang Spasi}

Suatu elemen seni yang mengacu pada jarak atau daerah antara, sekitar, di atas, di bawah, atau dalam benda, bisa digambarkan sebagai dua atau tiga dimensi, seperti datar, dangkal, atau dalam, terbuka atau tertutup, aktual, ambigu, atau khayalan.

Selain mempertimbangkan unsur-unsur kesenirupaan juga perlu dipertimbangkan prinsip-prinsip desain. Prinsip-prinsip desain meliputi: keseimbangan (balance), keselarasan (emphasis), pusat perhatian (eurythmy), harmoni, keterbatasan (limitation), komposisi (movement), proporsi (proporsion), ritma (rhythm), keutuhan (unity), dan variasi (variety) (Purnomo, 2004). 
Menganalisa dengan mengidentifikasi lebih lanjut urutan pengorganisasian suatu pekerjaan karya seni sebagaimana prinsip-prinsip seni yang digunakan untuk menyusun unsur-unsur desain, prinsip, dan komponen seni rupa di dalam suatu pekerjaan seni rupa.

\section{Interpretasi}

Interpretasi atau penafsiran maksud dan arti sebagai komunikasi ungkapan seniman dalam merasakan suasana hati, dan gagasan di dalam pekerjaan seni dengan mempertimbangkan kemampuan atau kelleluasaan pengetahuan berinovasi, proses kreatif, penguasaan lingkungan, histori, sosial, politik, filsafat, ekonomi.

1) Historis, Suatu upaya dalam membentuk urutan peristiwa yang berlangsung dan urutan itu merupakan aturan tingkah laku dari masa ke masa dalam peristiwa tertentu. Sedangkan sejarah dari sebuah karya adalah catatan perilaku perupanya dalam menarik suatu peristiwa saat itu untuk dicatat pada proses pembuatan karya dari masa ke masa.

2) Proses Kreatif, Ada pembaharuan bentuk karya dari yang lainnya, terutama teknik, bahan, dan hasil karyanya yang bertumpu pada proses.

3) Lingkungan, dalam menginterpretasi juga tak dapat lepas dari pandangan lingkungan karya itu diciptakan, baik fakta maupun kondisi perupa itu berada dalamperistiwa-peristiwa tertentu pada proses kratif berlangsung saat itu untuk merekam pada karya.

4) Sosial, Kegiatan sosial merupakan salah satu sebagai ide dasar untuk pembuatan karya seni rupa baik kegiatan yang ada di lingkungan kita maupun kegiatan sosial yang terjadi pada saat ini sang perupa dalam menciptakannya.

5) Politik, Politik pada umumnya mengkaji tentang pemerintahan dari Plato Machiavelli, Rousseau sampai Marx. Sedangkan studi pemerintahan adalah menggambarkan tentang struktur dan fungsi format pemerintahan. Yang di dalamnya termasuk kekuasaan sebagaimana yang terdapat dalam organisasi formal atau proses pemerintahan baik birokrasi maupun organisasi yang berhasil (Yudistira, 1996).

6) Baru / Inovasi, Karya yang baru dan berinovasi maksudnya adanya sesuatu yang baru baik dari tema, teknik, dan media. Sehingga karya yang ada tampak berbeda dibandingkan dengan yang sudah ada.

7) Filsafat, Filsafat berasal dari kata filosofia (Yunani) yang berarti melihat segala sesuatu dengan perhatian atau minat, ataupun berpikir tentang segala sesuatu dan hal itu disadarinya (Yudistira, 1996). Artinya dalam menginterpretasi dapat didasarkan pola pikir yang mendalam dan teliti melalui pikiran yang disadari.
8) Ekonomis, Penilaian sebuah karya secara ekonomis memang tidak mudah terutama adalah menilai karya yang murni seperi lukisan, patung. Secara ekonomi menilai karya kerajinan lebih mudah dibanding yang lain, karena karya kerajinan memang lebih condong pada orientasi ekonomi, sehingga untuk menghitung (kalkulasi) bahan produksi lebih mudah karena karya kerajinan biasanya di produk secara massal, sehingga proses kalkulasinya seperti pabrikasi barang secara umum. Untuk menghitung biaya produksi dimulai dari menghitung bahan baku, proses pembuatan, sumber daya manusia yang mengerjakan yang dihargai sesuai dengan biaya ketenagakerjaan. Demikian pula dalam menghitung harga jual telah diperhitungkan sejak awal dari produksi hingga biaya yang dikeluarkan pada proses penjualan.

9) Budaya, konsep awal tentang kebudayaan berasal E.B. Taylor yang mengemukakan bahwa culture atau cifilization ialah complex whole which includes knolege, belief, art, morals, law, custon, and any othercapabilities andhabits aquired by man as amember of society. Batasan tentang kebudayaan ini mengemukakan aspek kebendaan dan bukan kebendaan itu sendiri, atau materi dan non materi: sebagaimana Tyilor kemukakan bahwa kebudayaan ialah keseluruhan yang kompleks yang meliputi pengetahuan, kepercayaan, kesenian, moral, hukum, dan kemampuan-kemampuan lainnya serta kebiasaan yang diperoleh manusia sebagai anggota masyarakat. Kemudian Ralph Linton mengajukan batasan budaya secara lebih spesifik bahwa: a culture is the configuration of learned behavior whose components elemens are shered and transmitted by the members of a particular society. Pernyataan itu mengandung makna bahwasannya kebudayaan dianggap sebagai milik khas dari manusia (Yudistira, 19967).

Menilai sebuah karya seni rupa ataupun seni kerajinan tidak sekedar dengan cara yang subyektif, melainkan dengan cara yang dapat dipertanggungjawabkan. Penilaian sebuah karya dapat melalui teori alternative, yang mana sebuah karya seni kerajinan dapat dilihat dari segi kinerja dari pembuatannya yang menggunakan urutan kerja, ketepatan ukuran, kehalusan, ketepatan waktu, kemutahiran desain. Selain itu juga dilihat dari segi estetikanya, baik melalui unsure desain, prinsip desain, dan komponen seni rupa subject matter, meaning dan form dari karya itu sendiri. Serta penilaian ini dapat dilihat dari segi konsep temanya, antara lain: lingkungan, budaya, ekonomi, agama, alam, dan sebagainya.

\section{SIMPULAN}

Karya seni rupa yang indah maupun yang baik tidak mesti harus memenuhi dari keseluruhan kriteria penilaian secara utuh, baik dilihat dari kompnen seni yang berupa subject matter, form, dan meaning. Selain itu tidak juga 
secara keseluruhan hatus memenuhi syarat unsur-unsur seni baik itu garis, bidang, warna, nilai, format, dan ruang spasi. Dan juga harus memenuhi syarat dari prinsip-prinsip desain untuk mencapai sebuah karya yang harmoni, baik dalam komposisi, proporsi, keseimbangan, irama, pusat perhatian/penyelewengan, dan variasi.

Penilaian dapat dilakukan dengan lima langkah yaitu: langkah awal dengan mempertimbangkan komponen, unsur, dan prinsip desain. Identifikasi yang tentu mempertimbangkan perihal unsur dan prinsip desain. Analisis juga mempertimbangkan tentang unsur-unsur dan prinsip desain. Bentuk seperti apa karya yang telah disajikan, unsur, dan prinsip desain apakah yang telah diguankan sehingga karya ini dapat hadir. Sedangkan yang keempat adalah interpretasi yang harus mempertimbangkan perihal analisis dan dari sudut pandang lain untuk inspirasi hadirnya sebuah karya baik dari segi sejarah, budaya, sosial, plitik, filsafat, lingkungan, inovasi, ekonomi, dan proses kreatif itu sendiri. Dalam hal ini memang tidak harus semua dihadirkan, melainkan tergantung dari kehendak perupanya hendak dikembang ke mana karya yang akan dihadirkan.

Penjelasan di atas secara sederhana dapat disimpulkan pula bahwa sebenarnya pengukuran dalam penilaian karya seni rupa lebih condong pada relativitas, terutama adalah karya-karya yang lebih dekat dengan karakter seni murni yang lebih kuat pada penilaian kompnen, sedangkan karya desai lebih jelas pada perhitungan unsur dan prinsip desain, sedangkan karya desain lebih jelas pada perhitungan unsur, prinsip, dan segi ekonomi secara konkret. Dengan penjelasan tersebut diharapkan pembaca dalam menilai sebuah karya dapat memisahkan terlebih dahulu jenis karyanya dan memilah posisi kepentingan interpretasinya. Dengan demikian akan lebih jelas dan dapat menilai karya tersebut seni rupa secara objektif.

\section{DAFTAR PUSTAKA}

Purnomo, Heri. 2004. Nirmana Dwimatra. Yogyakarta: FBS UNY

Wong, Wucius. 1986. Beberapa Azas Merancang Dwi Matra. Terjemahan Adjat Sakri. Bandung: Institut Teknologi Bandung.

Sidik, Fajar dan Aming Prayitno. 1979. Desain Elementer. Yogyakarta: STSRI ASRI.

Garna, Yudistira K. 1996. Ilmu-Ilmu Sosial Dasar: Konsep-Dasar-Posisi. Bandung: Program Pascasarjana Universitas Pajajaran.

Sahman, Humar. 1993. Mengenai Dunia Seni Rupa. Semarang: IKIP Semarang Press. 